Psychological Medicine, 1989, 19, 5-13

Printed in Great Britain

\title{
EDITORIAL
}

\section{Congenital risk factors for schizophrenia ${ }^{1}$}

Technological advances in medicine often lead to a better understanding of disease processes. Computerized neuroimaging is an advance that has had a more profound impact than most. In schizophrenia, it has shown brain changes of at least a quantitative nature to exist in a significant minority of patients. Until recently, these changes were seen as evidence for an underlying neurodegenerative process : the dementia of dementia praecox. After all, the ventricular enlargement and cortical sulcal widening looked like cerebral atrophy and, from the beginning (Johnstone et al. 1976), a correlation between the radiological changes and degree of cognitive impairment in schizophrenic patients was noted. However, the expected correlation between length of illness and degree of ventricular dilatation stubbornly refused to emerge (Weinberger et al. 1979; Andreasen et al. 1982; Owens et al. 1985). Furthermore, changes of a similar degree were found in young patients only weeks or months after the onset of their first episode of schizophrenia (Turner et al. 1986). Most recently, follow-up computed tomographic studies have shown that the ventricular enlargement does not appear to progress over periods of up to seven years (Nasrallah et al. 1986; Illowsky et al. 1988; Reveley et al. 1988). These findings effectively rule out a progressive brain atrophy and have forced a reappraisal of the nature of such brain changes in schizophrenia. The changes are static, present at and, by inference, before the onset of the illness. Since major neurological events are seldom found to coincide with the onset of schizophrenia, the possibility arises that these changes represent long-standing non-progressive sequelae of much earlier events, events which could themselves be remote precursors of the illness. Consistent with this hypothesis is the handful of reports of sporadic cases of schizophrenia and similar psychoses in conjunction with a variety of gross brain lesions which are more obviously congenital: aqueduct stenosis (Reveley \& Reveley, 1983), corpus callosum agenesis (Lewis et al. 1988), cerebral hamartomata (Taylor, 1975) and arteriovenous malformations (Aleem \& Knesevich, 1987), perinatal ischaemic encephalopathy (Lewis, 1987), porencephaly (Owens et al. 1980), and septal (Lewis \& Mezey, 1985) and arachnoid cysts (Kuhnley et al. 1981). This view is also supported by recent neuropathological studies of the brains of schizophrenic patients. Limbic abnormalities found independently by three groups include unusual gyral patterns and reduced cortical thickness in the hippocampal region (Bogerts et al. 1985; Brown et al. 1986; Jakob \& Beckmann, 1986). The reported absence of gliosis accompanying these lesions would only be expected if these were the results of insult in infancy or before (Kolb et al. 1983; Bogerts, 1988).

This line of reasoning has quickly become elaborated, drawing on advances in other fields which have also reaped the benefits of new technology, in particular, neonatal medicine and developmental neuroanatomy. There now exist the rudiments of a working hypothesis about the nature of underlying mechanisms. Straws in the wind (Mednick, 1970; Fish, 1977; Bellak, 1979) preceded the recent emergence of fairly well-developed speculations, more or less independently, from several groups (Schulsinger et al. 1984; Murray et al. 1985) about what might broadly be called a 'neurodevelopmental' approach to schizophrenia (Murray \& Lewis, 1987).

\section{NEURODEVELOPMENTAL MODELS REVISITED}

This approach posits a very early brain lesion causing a lifelong disorder whose behavioural correlates change over time as a function of the maturation of the central nervous system. The result is a natural history in which subtle disturbances of attention and communication precede the pathognomonic picture of delusions, hallucinations and defect in adult life. The most refined

\footnotetext{
' Address for correspondence: Dr S. W. Lewis, Institute of Psychiatry, De Crespigny Park, London SE5 8AF.
} 
version of this approach has been formulated by Weinberger (1987) who states its central theme as follows: "It will be proposed that schizophrenia is a neurodevelopmental disorder in which a fixed brain lesion from early in life interacts with certain normal maturation events that occur much later. The thesis rests on the clinical maxim that the manifestations of a brain lesion vary with the state of brain maturation and involution'. Before considering evidence for the possible nature of this early lesion and the mechanisms by which it might exert its effects, it is worth looking back: how new is this idea?

Neurodevelopmental models have, for some time, occupied an important place in the understanding of childhood psychiatric disorders (Rutter, 1986). In one sense, the neglect of these models in adult disorders stems from the parochialism of those of us working in adult psychiatry, for whom patients, and so by implication their illnesses, begin at or beyond adolescence. In the case of schizophrenia the enormous efforts which have been made in defining a phenotype in crosssection have not yet been matched by proper consideration of longitudinal features. Yet Kraepelin stressed these longitudinal features, not only prospectively, but retrospectively. He considered that the peculiarities of personality which so often preceded the psychotic symptoms of dementia praecox should be regarded as the early manifestations of the same disease process.

In fact, the currently fashionable neurodevelopmental viewpoint in schizophrenia echoes a brief period 75 years ago when similar interpretations of similar observations of brain changes were made in Germany, America and Britain. Again, Kraepelin proposed in the eighth edition of his textbook (1913) that dementia praecox might have its 'internal' origins in early childhood. For instance, he noted that $10 \%$ of his Heidelberg series could be explained on the basis of cerebral infection during development. In America, eminent alienist-pathologists such as Rosanoff.(1914) and Southard (1915) considered that the morphological changes seen post-mortem in the brains of their dementia praecox patients were 'early hypoplasias' rather than atrophic lesions. Southard noted, 'The maldevelopment of the frontal region was probably of the nature of an interference with the development of tissues properly laid down embryologically.' Thus, 'a congenital or early acquired basis for the development of dementia praecox' was considered likely. In Britain, Watson (1910) and Bolton (1913) construed their own pathological observations in much the same way, noting cerebral anomalies particularly in prefrontal regions, which were probably of developmental origin, 'in the nature of a true sub-evolution'. Mackenzie (1912) pointed to the possible importance of 'intrauterine disease' and considered the possibility that some cases of dementia praecox were 'the victims of a brain deformity which does not manifest itself till late in life'. Turner (1912) likewise thought that dementia praecox resulted from developmental structural defects in the brain which only began to cause symptoms when adult life stresses supervened.

It seems that these early neurodevelopmental formulations were quickly overtaken by those of psychobiology and psychoanalysis. Rosanoff alone followed through his increasingly unfashionable ideas. An impressive series of twin studies eventually led him to propose a fully-fledged account of an interaction between genetic factors and early brain injury in the pathogenesis of schizophrenia. He considered (Rosanoff et al. 1934) 'a large proportion of cases of schizophrenia' to be late 'sequels' of 'birth trauma', in the same way as were some cases of epilepsy, drawing a distinction as distinct from 'permanent residuals, such as... mental deficiency' or 'immediate effects, such as stupor'. Sadly, those who acknowledged Rosanoff's findings were dismissive. In a review of the area, Slater (1953) concluded, 'There is no evidence that (early brain injuries) play a significant role in schizophrenia'.

\section{THE NEUROANATOMICAL LINK}

The main problem confronting the early theorists was the lack of a plausible mechanism by which a very early brain lesion, however incurred, might produce behavioural and cognitive changes after a gap of twenty or thirty years. The clinical observation made by Kraepelin and reiterated recently, that the gap is more apparent than real, with subtle abnormalities in these areas often predating the florid psychosis, is obviously important but throws little light on the underlying process. At about 
the same time as Rosanoff was pondering the long-term effects of perinatal brain injury in his twins, Kennard (1936) was embarking on a series of animal experiments which were for forty years to shape mainstream scientific opinion about the effects of such injury. Replicated many times by others, her results became enshrined in the so-called 'Kennard principle'. This held that the immature brain had powers of healing and reorganization not available to the mature brain. Thus, the behavioural sequelae of very early brain injury were far less drastic in the long term than those following similar injury sustained later in life. Such was the widespread acceptance of this general principle that an equally important observation made by Kennard was largely overlooked: where early injury did have sequelae, these often did not emerge until much later. Only over the past ten years has dogmatic adherence to the Kennard principle been seriously questioned (Schneider, 1979) and the importance of Kennard's second observation realized.

It is now clear that the natural history of functional impairments after early brain lesions is very variable and hinges on the interaction of a range of factors. The size, site and precise timing of the lesion are important, as are the species examined, and the effects of genes and exposure to different intervening environments (Finger \& Almli, 1984). Depending on these factors, impairments may indeed be transient or altogether absent. On the other hand, they may be immediate and permanent, or delayed in their expression for a considerable time. There are many examples of this last phenomenon in recent literature. In the rat, neonatal lesions of the somatosensory cortex only start to impair tactile responses at day 17 (Simons \& Finger, 1983), and neonatal ventral hypothalamic lesions only disturb appetite after day 50 (Isaacson, 1984). In primates, prefrontal lesions at or before birth are behaviourally quiescent until sexual maturity (Goldman \& Galkin, 1978). These observations of a latent period between cause and functional effect tie in with current models of normal neuroanatomical development.

Most of the cells of the CNS are generated during the first trimester in areas around the future ventricular system. In the following weeks the young neurones migrate to their final cortical destinations, guided by a radiating pattern of glial fibres (Rakic, 1978). This period of proliferation and migration constitutes the first main period during which adverse events can cause major changes in future brain structure and function, with such sequelae as hydrocephalus, craniofacial abnormalities and mental retardation. Less severe disruption to migration results in clusters of ectopic ('heterotopic') neurones (Mikhail \& Mattar, 1978). These have been demonstrated in several neurodevelopmental disorders, including dyslexia (Galaburda et al. 1983). Heterotopic neurones in the hippocampus in schizophrenia have also been shown (Kovelman \& Scheibel, 1983). The existence of a discrete time period during which cell migration is vulnerable to adverse environmental influences was elegantly shown by Otake \& Schull (1984), who found that the risk of severe mental retardation following the Hiroshima explosion was much higher if irradiation had occurred during the 8th-15th gestational week. The report of a similarly increased risk for later schizophrenia after second trimester exposure to the Helsinki influenza epidemic of 1959 (Mednick et al. 1988) is of interest here.

The second critical period of vulnerability occurs during subsequent consolidation of connections between neurones. A decade ago this phase of early brain development was broadly seen as a process of further expansion and consolidation. Neuronal migration preceded the growth and ramification of axons, and the establishment of synaptic connections. Lately, experimental evidence has led to a conceptual volte-face in which degenerative processes are seen as the more powerful force (Wigglesworth, 1984). As now conceived, the foetal brain after initial cell proliferation consists of an excess of diffusely interconnected neurones. During early development, a large proportion of these neurones die, the axons of the remainder thin out and retract to leave a mature skeleton of functional pathways, in a process called 'parcellation' (Ebbesson, 1984) or 'sculpting' (Janowsky $\&$ Finlay, 1986). The dual processes of neuronal fall-out and axon retraction occur to different degrees and at different, overlapping times in different brain regions. In the forebrain, these processes begin at about the eighth month of gestation and continue into the first month or two of postnatal life, and the proportion of cells normally eliminated ranges from some $50 \%$ in the basal ganglia and amygdala to over $90 \%$ in some layers of the cingulate cortex (Kane et al. 1984). 
Teleological explanations for this wholesale degeneration in the developing nervous system have included evolutionary diversification (Ebbesson, 1984) and the elimination of early, anomalous connections between cells (Janowsky \& Finlay, 1986). Whatever the reason, it seems that a brain insult during this critical period has the paradoxical effect of stabilizing immature patterns of cells and their connections. Normal neuronal and axonal degeneration slows down and halts in areas adjacent to brain lesions sustained during this time (Rakic \& Riley, 1983; Lund et al. 1984). In functional terms, this phenomenon seems to have twofold consequences for developing brain function. On the one hand it would appear to allow for future sparing of capacities which would normally have been mediated by the damaged region. On the other hand, it opens the way for the possible appearance of unexpected abnormalities not observed after adult lesions. These abnormalities may be in modalities of behaviour not directly referrable to the primary lesion. They have been explained in terms of the residual cortex becoming overloaded by all the functions now expected of it: so-called 'cortical crowding' (Whishaw \& Kolb, 1984). The emergence of such abnormalities may be delayed if the areas affected only normally come 'on line' at a mature stage of development, either because less specialized areas assume an equivalent role earlier in development (Goldman-Rakic, 1987), or because mature functioning awaits completed myelination or synapse elimination (Kolb \& Nonneman, 1976; Weinberger, 1987), processes which continue into adulthood in man (Richardson, 1982; Rakic et al. 1986).

Thus, the concept of near-limitless 'plasticity' in the immature nervous system (Lund, 1978) has become tempered with complex interactions between the variable local and remote effects of early lesions on involutional brain development. Direct experimental observation in animals and a new understanding of how the cytoarchitecture of the brain develops have shown, and to some extent explained, how very early brain insults can have long-delayed, unexpected effects on behaviour. The critical period for such insults to the telencephalon are the months around birth. These lines of evidence have been marshalled in support of the neurodevelopmental approach to cause in schizophrenia and attention has turned to considering the nature of such putative early lesions.

\section{OBSTETRIC COMPLICATIONS AND SCHIZOPHRENIA}

Until recently cerebrovascular accidents occurring before and at the time of birth were thought to be uncommon and to carry a grave prognosis (Larroche, 1984). This impression was gained from the necessary reliance on highly selected samples of neonates coming to post mortem. Subsequently, neuroimaging techniques have revealed that these events are far from uncommon and, in all but the most extensive injuries, have a relatively good outcome, at least in the short term. Hypoxia is the main cause of ischaemic-haemorrhagic injury (Volpe, 1987). This can result from perinatal asphyxia or, more commonly, from asphyxia during pregnancy secondary to placental insufficiency, maternal disease, or antepartum haemorrhage (Sinha et al. 1985). Pre-term or low birthweight babies are particularly at risk (De Vries et al. 1985). Patterns of injury are largely dictated by the stage of development of the brain. Intraventricular haemorrhage with periventricular ischaemia is common, as is ischaemic damage to especially vulnerable structures such as parts of the cerebral cortex in frontal and occipital regions, hippocampus and subiculum (Volpe, 1987). Radiological sequelae documented in follow-up studies into infancy include non-progressive dilatation of lateral and third ventricles, cortical sulcal widening and cystic degeneration of infarcted areas (Liechty et al. 1983).

Eight independent controlled studies over the past twenty years have examined possible links between schizophrenia and a history of presumed obstetric complications. The studies differ widely in diagnostic criteria, sampling, and the definition and assessment of obstetric complications. Control groups have included normal siblings (De Lisi et al. 1987), matched normal unrelated controls (McNeil \& Kaij, 1978) and other psychiatric patients (Lewis \& Murray, 1987). Although general operational definitions of obstetric complications are available (Prechtl, 1967) these have seldom been used. As a result, which events are, and which events are not, considered complications varies between studies. Despite these discrepancies, and the variety of hypotheses as to the 
mechanism at work-organic (Parnas et al. 1982), psychosocial (Woerner et al. 1973) or anthropometric (Lane \& Albee, 1966) - seven of the eight studies reported a significant excess of obstetric complications in the schizophrenic group (Lane \& Albee, 1966; Woerner et al. 1973; McNeil \& Kaij, 1978; Jacobsen \& Kinney, 1980; Parnas et al. 1982; Gillberg et al. 1986; Lewis \& Murray, 1987; DeLisi et al. 1987). In line with the predictions of Rosanoff et al. (1934), a history of obstetric complications appears to predict an earlier onset by two or three years (Pollack \& Greenberg, 1966; DeLisi et al. 1987; Owen et al. 1988).

As noted, this consensus of results hides a wide discrepancy in methodology between studies. Paradoxically, the main similarity between the studies is their chief collective weakness: the use of retrospective assessment of obstetric histories, even if assessed blindly. This method has obvious limitations. Although it was the basis for the famous series of studies by Pasamanick and colleagues which led to his aphoristic 'spectrum of reproductive casualty' (Pasamanick, 1961), it is obviously far from ideal. Even standardized hospital birth records (McNeil \& Kaij, 1978; Gillberg et al. 1986) are prone to error when collected in a clinical setting (Joffe \& Grisso, 1985). The cotwin control method, usually a powerful method of isolating environmental risk factors, is open to similar inaccuracy. Assigning the right obstetric history to the right twin cannot be done with confidence, although the claim that adverse obstetric events occur in the schizophrenic twin in discordant monozygotic pairs is a thread which has run through twin studies from the beginning (Essen-Moller, 1941 ; Kallman, 1946; Inouye, 1963; Pollin \& Stabenau, 1968; Torrey, 1977). One way round the problem is to compare within-pair birthweight differences in discordant pairs to that in concordant pairs. Lewis et al. (1987) found mean intrapair birthweight difference to be four times greater in monozygotic pairs later to be discordant for schizophrenia, compared to that in pairs later to be concordant. These findings point to the relative importance of early, probably prenatal, environmental factors in twins discordant for schizophrenia.

Despite these methodological difficulties, the evidence as it stands suggests that obstetric complications can be a risk factor for schizophrenia, just as they seem to be for several neurodevelopmental disorders of childhood (Gillberg \& Gillberg, 1983; Taylor et al. 1985). Available data can be used to estimate roughly how important a risk factor this might be. Goodman (1988) reanalysed the Danish adoption study data of Jacobsen \& Kinney (1980) to show a relative risk of schizophrenia of 2.5:1 in those probands with a history of obstetric complications, compared to those without. The published data from another population-based study, that by Gillberg et al. (1986) of 'teenage psychoses', many of which were schizophrenic, allow a similar calculation which gives a similarly increased risk of $2 \cdot 1: 1$ for those with 'non-optional' births. Whether or not this is a truly causal association, and if so what mechanism might be at work, are more difficult issues. None of the studies from thirteen different centres, mostly reported in the early 1970 s, found an increased rate of obstetric complications in schizophrenic mothers giving birth (reviewed in McNeil \& Kaij, 1978) and it seems safe to dismiss this as a possible source of artefact. It is known that obstetric complications are related to low socioeconomic class but several of the foregoing studies used control groups well-matched for age, sex, social class and hospital of delivery, so making socioeconomic confounding factors unlikely. Possible psychosocial mediators such as deviant rearing practices following difficult pregnancies are also unlikely given the findings of Jacobsen \& Kinney (1980) that the increased risk persists despite adoption-away at birth. The argument that obstetric complications and schizophrenia enjoy a more direct link founded in an organic mechanism has sought credence from a recently reported association between a history of complications and the very findings which stimulated recent neurodevelopmental formulations: morphological abnormalities in the brain in schizophrenia.

Lateral ventricular enlargement and widened cortical sulci, which are the best replicated findings in schizophrenia, have also been reported in several childhood neurodevelopmental disorders (Bergstrom et al. 1984), and are frequent, non-progressive radiological sequelae of pre- and perinatal hypoxic-ischaemic injury (Volpe, 1987; De Vries et al. 1985). Seven CT studies have looked for an association between these changes in schizophrenia and a history of obstetric complications : each has yielded slightly different results. Reveley et al. (1984) found a highly significant association 
between lateral ventricular size and a reported history of obstetric complications in their control sample of 18 normal twins, but no such association was evident in 21 schizophrenic twins. Schulsinger et al. (1984), in the only CT study so far to use birth records, examined ventricular size in 27 young adult offspring of schizophrenic mothers. The seven schizophrenic members of this sample had the largest ventricles, significantly higher than those in the 11 schizotypal non-psychotic members. Although total obstetric complication score did not correlate with ventricular size, low birthweight did (Silverton et al. 1985). A history of obstetric complications has elsewhere been shown to correlate positively with lateral ventricular size (Turner et al. 1986), frontal horn area (DeLisi et al. 1986) and a combination of ventricular and sulcal widening (Owen et al. 1988). No significant correlations were found in two other studies (Pearlson et al. 1985; Nimgaonkar et al. 1988). It is fair to say that the case for an association between quantitative brain abnormalities in schizophrenia and a history of obstetric complications remains as yet unproven. However, given the small sample sizes and the problems in assessing obstetric histories in most of these studies, the likelihood of Type II error is considerable. Rigorous attempts at replication using validated, standardized assessments and larger samples are needed.

\section{GENES, ENVIRONMENT AND BRAIN DEVELOPMENT}

The term obstetric complications is a wide one, covering a multitude of often interdependent pathological events: metabolic, cerebrovascular, traumatic, infectious, both at and before birth. There is no firm evidence to implicate any single such event as a specific risk factor for schizophrenia. It is perhaps simplistic to assume that this might be the case. Even with a syndrome whose congenital origins are undisputed, such as cerebral palsy, dispute still rages as to which events, if any, are crucial in pathogenesis (Paneth, 1986). What is common to these disparate events is their timing. If obstetric complications are a true risk factor, there is no reason to suppose that this might not be true for other cerebral insults if sustained during this critical period of early brain development. Childhood head injury and encephalitides, for example, also seem to be occasional risk factors for schizophrenia (Nunn et al. 1986; Wilcox \& Nasrallah, 1987), as well as being events with demonstrable radiological sequelae such as non-progressive ventricular enlargement (Meyers et al. 1983).

Nor need early cerebral lesions be environmentally mediated. This review has focused on these because their nature is at present better understood, but in epidemiological terms specific environmental risk factors for schizophrenia are less well-established and probably less important than genetic factors. We have few clues as to the mechanism by which genetic factors operate in schizophrenia, but again age-dependent effects probably play a large part. In those unusual cases where autosomal neurodegenerative disorders such as Huntington's disease produce schizophrenic symptoms, age at expression of the disorder seems to dictate this (Weinberger, 1987; Propping \& Friedl, 1988). Recent evidence suggests that $30 \%$ of the entire human genome is expressed only in the brain (Sutcliffe et al. 1984) and the opportunities for genes directly to affect normal and abnormal brain development is immense. Genes can selectively influence neurone migration and involution in specific brain areas, just as can viral infections (Johnson, 1982). For example, experiments in mice have turned up several autosomal genes which affect cell migration to the hippocampus, resulting in abnormal patterns of heterotopic neurones, some functioning normally, some not (Nowakowski, 1987). Variable penetrance means that affected animals vary in the degree of hippocampal malformation which results, and even as to which side of the brain is the more affected. Just as parallels have been drawn between genetic neocortical heterotopias in mice and those reported in dyslexia (Sherman et al. 1985), these genetic hippocampal heterotopias might yet elucidate genetic mechanisms in schizophrenia.

In summary, the evidence for the importance of early brain lesions in schizophrenia is intriguing, but as yet circumstantial. Nonetheless, similar formulations are already emerging for other 'adult' brain disorders such as Alzheimer's disease, Parkinson's disease (Calne et al. 1986) and multiple sclerosis (Elias, 1987). Odd epiphenomena of schizophrenia such as the season-of-birth effect, the 
subtle neurological signs and physical anomalies, pre-morbid intellectual impairments and the sex effect on age of onset have all been offered as grist to the neurodevelopmental mill (Murray \& Lewis, 1987). In the end, the most important product of the debate so far has been the redrawing of the battle lines in the search for causes in schizophrenia. Overdue recognition of the likely importance of the timing of brain lesions in the pathogenesis of schizophrenia has brought a fresh perspective to what had threatened to become a sterile advocacy of the importance of one brain region over another (Andreasen, 1986). Future insights will undoubtedly come both from the use of recombinant DNA technology and neuroimaging in understanding processes at work in brain development, normal and abnormal. More specifically, the true status of the possible early risk factors for schizophrenia now being mooted can only come from long-term longitudinal studies of large cohorts. At the very least, the neurodevelopmental viewpoint is generating testable hypothesis in schizophrenia research. That their adequate testing will require many more years of work should not detract from the interest of these hypotheses; nor should the fact that this new viewpoint is actually seventy-five years old.

SHÔN W. LEWIS

\section{REFERENCES}

Aleem, A. \& Knesevian, M. A. (1987). Schizophrenia-like psychosis associated with vein of Galen malformation: a case report. Canadian Journal of Psychiatry 32, 226-227.

Andreasen, N. C. (1986), (ed.) Can Schizophrenia be Localised in the Brain? American Psychiatric Press: Washington DC.

Andreasen, N. C., Olsen, S. A., Dennert, J. W. \& Smith, M. R. (1982). Ventricular enlargement in schizophrenia: relationship to positive and negative symptoms. American Journal of Psychiatry 139, $297-302$.

Bellak, L. (1979). Schizophrenic syndrome related to minimal brain dysfunction: a possible neurological subgroup. Schizophrenia Bulletin 5, 480-489.

Bergstrom, K., Bille, B. \& Rasmussen, F. (1984). Computed tomograph of the brain in children with minor neurodevelopmental disorders. Neuropaediatrics 15, 115-119.

Bogerts, B. (1988). Limbic and paralımbic pathology in schizophrenia. In Schizophrenia: A Scientific Focus (ed. C. A. Tamminga and $C$. Schulz). OUP: New York (in the press).

Bogerts, B., Meertz, E. \& Schonfeldt-Bausch R. (1985). Basal ganglia and limbic system pathology in schizophrenia. Archives of General Psychiatry 42, 784-791.

Bolton, J. S. (1913). A contribution to the localisation of cerebral function, based on the clinico-pathological study of mental disease. Journal of Mental Science 59, 26-148.

Brown, R., Colter, N., Corsellis, J., Crow, T., Frith, C. D., Jagoe, R., Johnstone, E. C. \& March, L. (1986). Post-mortem evidence of structural brain changes in schizophrensa. Archives of General Psychiatry 43, 36-42.

Calne, D. B., Eisen, A., McGeer, E. \& Spencer, P. (1986). Alzheimer's disease, Parkinson's disease and motor neurone disease: abiotrophic interaction between ageing and environment? Lancet ii, 1076-1090.

DeLisı, L. E., Goldin, L. R., Hamovit, V. R., Maxwell, M. E., Kurtz, D. \& Gershon, E. S. (1986). A family study of the association of increased ventricular size with schizophrenia. Archives of General Psychiatry 43, 48-53.

DeLisi, L. E., Goldin, L. R., Maxwell, M. E., Kazuba, D. M. \& Gershon, E. S. (1987). Clinical features of illness in siblings with schizophrenia or schizoaffective disorder. Archives of General Psychiatry 44, 891-899.

De Vries, L. S., Dubowitz, L. M. S., Dubowitz, V., Kaiser, A., Lary, S., Silverman, M., Whitelaw, A. \& Wigglesworth, J. S. (1985). Predictive value of cranial ultrasound in the newborn baby. Lancet ii, 137-140.

Ebbesson, S. O. (1984). Evolution and ontogeny of neural circuits. Behavioural Brain Sciences 7, 321-366.
Elias, S. B. (1987). Oligodendrocyte development and the natural history of multiple sclerosis: a new hypothesis for the pathogenesis of the disease. Archives of Neurology 44, 1294-1299.

Essen-Moller, E. (1941). Psychratrische Untersuchungen an einer Serie von Zwillingen. Acta Psychiatrica Scandinavica (Suppl.), 23.

Finger, S. \& Alml1, C. R. (1984). Early Brain Damage, Vol. 22. Neurobiology and Behaviour. Academic Press: Orlando, Florida.

Fish, B. (1977). Neurobiologic antecedents for schizophrenia in children: evidence for an inherited, congenital neurointegrative defect. Archives of General Psychiatry 34, 1297-1313.

Galaburda, A. M., Sherman, G. F. \& Geschwind, N. (1983). Developmental dyslexia: third consecutive case with cortical anomalies. Society of Neuroscience Abstracts 9, 940.

Gillberg, C. \& Gillberg, I. C. (1983). Infantile autism: a total population study of reduced optimality in the pre-, peri- and neonatal period. Journal of Autism and Developmental Disorders 13, $153-166$.

Gillberg, C., Wahlstrom, J., Forsman, A., Hellgren, L. \& Gillberg, I. C. (1986). Teenage psychoses - epidemiology, classification and reduced optimality in the pre- and perinatal periods. Journal of Child Psychology and Psychiatry 27, 87-96.

Goldman, P. S. \& Galkin, T. W. (1978). Prenatal temoval of frontal association cortex in the fetal rhesus monkey: anatomical and functional consequences in postnatal life. Brain Research 152, $451-485$.

Goldman-Rakic, P. S. (1987). Development of cortical circuitry and cognitive function. Child Development 58, 60l-622.

Goodman, R. (1988). Are complications of pregnancy and birth causes of schizophrenia? Developmental Medicine and Child Neurology 30, 391-394.

Illowsky, B., Juliano, D. M., Bigelow, L. B. \& Weinberger, D. R. (1988). Stability of CT scan findings in schizophrenia Journal of Neurology, Neurosurgery and Psychiatry 51, 209-212.

Inouye, E. (1963). Similarity and dissimilarity of schizophrenia in twins. In Proceedings, Third World Congress of Psychiatry, 1961, Vol. 1. University of Toronto Press: Montreal.

Isaacson, R. L. (1984). Hippocampal damage: effects on dopaminergic systems of the basal ganglia. In International Review of Neurobiology, vol. 25 (ed. R. J. Bradley and J. R. Smythies), pp. 260-305. Academic Press: New York.

Jacobson, B. \& Kinney, D. K. (1980). Perinatal complications in adopted and non-adopted schizophrenics and their controls. Acta Psychiatrica Scandinavica 62 (Suppl. 285), 317.

Jakob, H. \& Beckmann, H.(1986). Prenatal development disturbances in the limbic allocortex in schizophrenics. Journal of Neural Transmission 65, 303-326.

Janowsky, J. S. \& Finlay, B. L. (1986). The outcome of perinatal 
brain damage. Developmental Medicine and Child Neurology 28, 375-389.

Joffe, M. \& Grisso, J. A. (1985). Comparison of ante-natal hospital records with restrospective interviewing. Journal of Biosocial Science 17, 113-119

Johnson, R. T. (1982). Viral Infections of the Nervous System. Raven: New York.

Johnstone, E, Crow, T. J., Frith, C. D., Husband, J. \& Kreel, L. (1976). Cerebral ventricular size and cognitıve impairment in chronic schizophrenia. Lancet ii, 924-926.

Kallman, F. J. (1946) The genetic theory of schizophrenı: an analysis of 691 schizophrenic twin index families. American Journal of Psychiatry 103, 309-322.

Kane, M. H., Sengelaub, D. R. \& Finlay, B. L. (1984). An autoradiographic analysis of the role of cell death in the regulation of neocortical cell number. Neuroscience Abstracts 10, 462.

Kennard, M. A. (1936). Age and other factors in motor recovery from precentral lesions in monkeys. American Journal of Physiology 115. 138-146.

Kolb, B \& Nonneman, A. J. (1976). Functional development of the prefrontal cortex in rats continues in adolescence. Science 193, 335-336.

Kolb, B., Sutherland, R. J. \& Whishaw, J. Q. (1983). Abnormalitıes in cortical and subcortical morphology after neonatal lesions in rats. Experimental Neurology 79, 223-244.

Kovelman, J. A. \& Scheibel, A. B. (1983). A neuroanatomical correlate of schizophrensa. Society of Neuroscience Abstracts 9, 850.

Kovelman, J. A. \& Scheibel, A. B. (1984). A neurohistological correlate of schizophrenia. Biological Psychiatry 19, 1601-1621.

Kraepelin, E. (1913). Psychiatrte, Vol. 3, 8th edn, translated 1919 as: Dementia Praecox and Paraphrenia. Livingstone: Edinburgh.

Kuhnley, E. J., White, D. H. \& Granoff, A. L. (1981). Psychiatric presentation of arachnoid cyst. Journal of Clinical Psychiatry 42, 167-169.

Lane, E. \& Albee, G. W. (1966). Comparative birthweights of schizophrenics and their siblings Journal of Psychology 64, 227-231.

Larroche, J-C. (1984). Perinatal brain damage. In Greenfield's Neuropathology, 4th edn (ed. J. H. Adams, J. A. N. Corsellis and L. W. Duchen), pp. 451-490. John Wiley: New York.

Lewis, S. W. (1987). Brain imaging in a case of Capgras' syndrome. British Journal of Psychiatry 150, 117-121.

Lewis, S. W. \& Mezey, G. C. (1985). Clınical correlates of septum pellucidum cavities: an unusual association with psychosis. Psychological Medicine 15, 43-54.

Lewis, S. W. \& Murray, R M. (1987). Obstetric complications, neurodevelopmental deviance and schizophrenia. Journal of Psychiatric Research 21, 413-421.

Lewis, S. W., Chitkara, B., Reveley, A. M. \& Murray, R. M. (1987). Family history and birthweight in monozygotic twins concordant and discordant for psychosis. Acta Geneticae Medicae et Gemellologiae 36, 267-273.

Lewis, S. W., Reveley, M. A., David, A. S. \& Ron, M. A. (1988). Agenesis of the corpus callosum and schizophrenia. Psychological Medicine 18, 341-347.

Liechty, E. A., Gilmor, R. L., Bryson, C. Q. \& Bull, M. J. (1983). Outcome of high risk neonates with ventriculomegaly. Developmental Medicine and Child Neurology 25, 162-168.

Lund, R. D. (1978). Development and Plasticity of the Brain. Oxford University Press: New York.

Lund, R. D., Chang, F. L. F. \& Land, P. W. (1984). The development of callosal projections in normal and one-eyed rats. Developmental Brain Research 14, 139-142.

Mackenzie, I. (1912). The physical basis of mental disease. Journal of Mental Science 58, 405-477.

McNeil, R. F. \& Kaij, L. (1978). Obstetric factors in the development of schizophrenia. In The Nature of Schizophrenia (ed. L. C. Wynne, R. L. Cromwell and S. Matthysse), pp. 401-429. John Wiley: New York.

Mednick, S. A. (1970). Breakdown in individuals at high risk for schizophrenia : possible predisposing factors. Mental Hygiene 54, $50-56$.

Mednick, S. A., Machon, R. A., Huttenen, M. O. \& Bonnett, D. (1988). Adult schizophrenia following prenatal exposure to an influenza epidemic. Archives of General Psychiatry 45, 189-192.

Meyers, C. A., Levin, H.S., Eisenberg, H. M. \& Guinto, F.C. (1983). Early versus late lateral ventricular enlargement following closed head injury. Journal of Neurology, Neurosurgery and Psychiatry 46, 1092-1097.

Mikhail, M. A. \& Mattar, A. G. (1978). Malformations of the cerebral cortex with heterotopia of the grey matter. Journal of Computer Assisted Tomography 2, 291-296.

Murray, R. M. \& Lewis, S. W. (1987). Is schizophrenia a neurodevelopmental disorder? British Medical Journal 295, 681-682.

Murray, R. M., Lewis, S. W. \& Reveley, A. M. (1985). Towards an aetiological classification of schizophrenia. Lancet i, 10231026.

Nasrallah, H. A., Olsen, S. C., McCalley-Whitters, M., Chapman, S. \& Jacoby, E. C. (1986). Cerebral ventricular enlargement in schizophrenia a preliminary follow-up study. Archives of General Psychiatry 43, 157-159.

Nimgaonkar, V. L., Wessley, S. \& Murray, R. M. (1988). Prevalence of familialıty, obstetric complications and structural brain damage in schizophrenic patients. British Journal of Psychiatry 153, 191-197.

Nowakowski, R. S. (1987). Basic concepts of CNS development. Child Development 58, 568-595.

Nunn, K. P., Lask, B. \& Cohen, M. (1986). Viruses, neurodevelopmental disorder and childhood psychosis. Journal of Child Psychology and Psychiatry 27, 55-64.

Otake, M. \& Schull, W. J. (1984). In utero exposure to A-bomb radiation and mental retardation: a reassessment. British Journal of Radiology 57, 409-414.

Owen, M. J., Lewis, S. W. \& Murray, R. M. (1988). Obstetric complications and schizophrenia: a computed tomographic study Psychological Medicme 18, 332-340.

Owens, D. G. C., Johnstone, E. C., Bydder, G. M. \& Kreel, L. (1980). Unsuspected organic disease in chronic schizophrenia demonstrated by computed tomography. Journal of Neurology, Neurosurgery and Psychiatry 43, 1065-1069.

Owens, D. G. C., Johnstone, E. C., Crow, T. J., Frith, C. D., Jagoe, V. R. \& Kreel, L. (1985). Lateral ventricular size in schizophrenia: relationship to the disease process and its clinical limitations. Psychological Medicine 15, 27-41.

Paneth, N. (1986). Birth and the origins of cerebral palsy. New England Journal of Medicine 315, 124-126.

Parnas, J., Schulsinger, F., Teasdale, T. W., Schulsinger, H., Feldman, P. M. \& Mednick, S. A. (1982). Perinatal complications and clinical outcome withn the schizophrenia spectrum. British Journal of Psychiatry 140, 416-420.

Pasamanick, B. (1961). Epidemiological investigations of some prenatal factors in the production of neuropsychiatric disorder. In Comparative Epidemiology of the Mental Disorders (ed. P. H. Hock and J. Zubın), pp. 260-275. Grune \& Stratton: London.

Pearlson, G. D., Garbacz, D. J., Moberg, P. J., Ahn, H. S. \& De Paulo, J. R. (1985). Symptomatic, familial, perinatal and social correlates of CAT changes in schizophrenics and bipolars. Journal of Nervous and Mental Disease 173, 4250.

Pollack, M. \& Greenberg, I. M. (1966). Paranatal complications in hospitalised schizophrenic and nonschizophrenic patients. Journal of the Hillside Hospital 15, 191-197.

Pollin, W. \& Stabenau, J. R. (1968). Biological, psychological and historical differences in a series of monozygotic twins discordant for schizophrenia. In The Transmission of Schizophrenia (ed. D. Rosenthal and S. S. Kety), pp. 317-332. Pergamon: Oxford.

Prechtl, H. (1967). Neurological sequelae of prenatal and perinatal complications. British Medical Journal iv, 763-767.

Propping, P. \& Friedl, W. (1988). Genetic studies of biochemical, pathophysiological and pharmacological factors in schizophrenia. In Handbook of Schizophrenia, Vol. 3. Nosology, Epidemiology and Genetics (ed. M. T. Tsuang and J. C. Simpson), pp. 579608. Elsevier: New York. 
Rakic, P. (1978). Neuronal migration and contact guidance in the primate telencephalon. Post-Graduate Medical Journal 54, 2540 .

Rakic, P. \& Riley, K. P. (1983). Regulation of axon number in primate optic nerve by prenatal binovular competition. Nature 305, $135 \quad 137$

Rakic. P., Bourgeois, J., Eckenhoff, M. F., Zecevic, N., GoldmanRakic, P. (1986). Concurrent overproduction of synapses in diverse regions of the primate cerebral cortex. Science 232, 232-235.

Reveley, A. M. \& Reveley, M. A. (1983). Aqueduct stenosis and schizophrenia. Journal of Neurology, Neurosurgery and Psychiatry 46, 1822.

Reveley, A. M., Reveley, M. A. \& Murray, R. M. (1984). Cerebral ventricular enlargement in non-genetic schizophrenia : a controlled twin study. British Journal of Psychiatry 144, 89-93.

Reveley, M. A., Chitkara, B. \& Lewis, S. W. (1988). Ventricular and cranial size in schizophrenia: a 4 to 7 year follow-up. Paper presented at the Fourth Winter Workshop on Schizophrenia, Austria, 24 January.

Richardson, E. P. (1982). Myelination in the human nervous system. In Histology and Histopathology of the Nervous System, Vol. I (ed. W. Haymaker and R. D. Adams), pp. 146-173. Thomas: Springfield.

Rosanoff, A. J. (1914). A study of brain atrophy in relation to insanity. American Journal of Insanity 70, 101-132.

Rosanoff, A., Handy, L., Plesset, I. \& Brush, S. (1934). The etiology of so-called schizophrenia psychoses. American Journal of Psychiatr. 91, 247286.

Rutter, M. (1986). Child psychiatry: the interface between clinical and developmental research. Psychological Medicine 16, 151169.

Schneider, G. E. (1979). Is it really better to have your brain lesion early? Revision of the Kennard principle. Neuropsychologia 17, 557584.

Schulsinger, F., Parnas, J., Petersen, E. T., Schulsinger, H., Teasdale, T. W., Mednick, S. A., Moller, L. \& Silverton, L (1984). Cerebral ventricular size in the offspring of schizophrenic mothers: a preliminary study. Archives of General Psychiatry 41, 602-606.

Sherman, G. F., Galaburda, A. M. \& Geschwind, N. (1985). Cortical anomalies of brains of New Zealand mice: a neuropathologic model of dyslexia. Proceedings of the National Academy of Sciences, USA 82, 8072-8074.

Silverton, L., Finello, K. M., Schulsinger, F. \& Mednick, S. A. (1985). Low birth weight and ventricular enlargement in a high-risk sample. Journal of Abnormal Psychology 94, 405-409

Simons, D. \& Finger, S. (1983). Neonatal versus later sensorimotor cortex damage: the ability to use spared fragments of target tissue to guide tactile learning. Physiological Psychology 11, 29-34.

Sinha, S. K., Davies, J. M., Sims, D. G. \& Chiswick, M. L. (1985).
Relation between periventricular haemorrhage and ischaemic brain lesions diagnosed by ultrasound in very preterm infants. Lancel ii, 1154-1156.

Slater, E. (1953). Psychotic and Neurotic Illnesses in Twins. HMSO London.

Southard, E. E. (1915). On the topographical distribution of cortex lesions and anomalies in dementia praecox, with some account of their functional significance. American Journal of Insanity 71, 603-671.

Sutcliffe, J. G., Milner, R. J., Gottesfeld, J. M. \& Reynolds, W. (1984). Control of neuronal gene expression. Sctence 225 1308-1315.

Taylor, D. C. (1975). Factors influencing the occurrence of schizophrenia-like psychosis with TLE. Psychological Medicine 5. 249-257.

Taylor, D. J., Howie, P. W., Davison, J., Davıson, D. \& Drillien, C. M. (1985). Do pregnancy complications contribute to neurodevelopmental disability? Lancet i, $713-716$.

Torrey, E. F. (1977). Birth weights, perinatal insults and HLA types: return to 'orıginal sin'. Schizophrenia Bulletin 3, 347-351.

Turner, J. (1912). The classification of insanity. Journal of Mental Science 58, 1-25.

Turner, S. W., Toone, B. K. \& Brett-Jones, J. R. (1986). Computed tomographic scan changes in early schizophrenia - preliminary findings. Psychological Medicine 16, 219-226.

Volpe, J. J. (1987). Neurology of the Newborn. W. B. Saunders: Philadelphia.

Watson, G. A. (1910). Observations on the morbic anatomy of mental disease. Journal of Mental Science 56, 227-252.

Weinberger, D. R. (1987). Implications of normal brain development for pathogenesis of schizophrenia. Archives of General Psychiatry 44, 660-669.

Weinberger, D. R., Torrey, E. F., Neophytides, A. \& Wyatt, R. J. (1979). Lateral ventricular enlargement in chronic schizophrenia. Archives of General Psychiatry 36, 735-739.

Whishaw, I. O. \& Kolb, B. (1984). Behavioural and anatomical studies of rats of complete or partial decortification in infancy. In Early Brain Damage, Vol. 2 (ed. S. Finger and C. R. Almlı), pp. 117-138. Academic Press: Orlando, Florida.

Wigglesworth, J. (1984). Brain development and its modification by adverse influences. In The Epidemiology of the Cerebral Palsies. Clinics in Developmental Medicine, No. 86 (ed. F. Stanley and E. Alberman), pp. 12-26. Blackwell: Oxford.

Wilcox, J. A \& Nasrallah, H. A. (1987). Childhood head trauma and psychosis. Psychiatry Research 21, 303307

Woerner, M. G., Pollack, M.\& Klein, D. F. (1973) Pregnancy and birth complications in psychiatric patients. Acta Psychiatrica Scandinavica 49,712-721. 